J. Lake Sci. (湖泊科学) , 2021, 33(2): 607-621

DOI 10. 18307/2021. 0225

(c) 2021 by Journal of Lake Sciences

\title{
基于实测与模拟的青海湖冰厚时空变化特征”
}

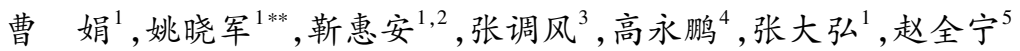

(1: 西北师范大学地理与环境科学学院,兰州 730070)

(2: 甘肃林业职业技术学院, 天水 741020)

(3: 青海省气候中心, 西宁 810000$)$

(4:云南大学国际河流与生态安全研究院,昆明 650091)

(5: 青海省气象科学研究所,西宁 810000$)$

摘 要: 湖冰厚度是湖泊在封冻期的重要物理参数,明晰其时空变化特征对于认识气候变暖背景下的湖冰响应规律具有 重要的理论价值和现实意义. 基于 ERA5 Climate Reanalysis 气温数据集、MODIS MOD09GQ 数据产品和 2019 年湖冰钻孔 测厚数据及雷达测厚数据, 重建 2000-2019 年青海湖冰厚时间序列并分析其时空变化特征. 结果表明: (1)2019 年 3 月实 测青海湖湖冰厚度平均增长速率为 $0.30 \mathrm{~cm} / \mathrm{d}$, 高于 2 月份 $(0.12 \mathrm{~cm} / \mathrm{d})$. 基于度日法湖冰生长模型模拟的 2018 年 11 月2019 年 3 月青海湖冰厚平均增长速率为 $0.34 \mathrm{~cm} / \mathrm{d}$, 与实际观测数据相比, 模拟冰厚误差为 $\pm 2 \mathrm{~cm}$, 但在河流人湖口处和 湖区南侧误差较大, 且冰厚模拟数值在 3 月中旬前高估而之后有所低估. (2)青海湖多年平均冰厚介于 $32 \sim 37 \mathrm{~cm}$, 其中 2008-2016 年湖冰厚度年际变化剧烈, 呈现先增大再稳定后减小的趋势. 冻结初期湖冰厚度增长迅速, 12 月和 1 月湖冰 增长速率分别为 0.45 和 $0.41 \mathrm{~cm} / \mathrm{d}, 2$ 月后冰厚增长速率放缓, 2 月和 3 月分别为 0.29 和 $0.14 \mathrm{~cm} / \mathrm{d}$. (3)2000-2019 年冰厚 整体呈现北厚南薄、东厚西薄的空间格局, 多年冰厚变化幅度湖区西部较东部稳定, 湖冰平均厚度与完全封冻时长及封 冻期呈正相关.

关键词: 湖冰;冰厚;机载测冰雷达;度日法湖冰生长模型;青海湖

\section{Spatiotemporal variation of ice thickness of Lake Qinghai derived from field measurements and model simulation*}

Cao Juan ${ }^{1}$, Yao Xiaojun ${ }^{1 * *}$, Jin Hui'an ${ }^{1,2}$, Zhang Tiaofeng ${ }^{3}$, Gao Yongpeng ${ }^{4}$, Zhang Dahong ${ }^{1} \&$ Zhao Quanning $^{5}$

(1: College of Geography and Environmental Science, Northwest Normal University, Lanzhou 730070, P.R.China)

(2: Gansu Forestry Technological College, Tianshui 741020, P.R.China)

(3: Qinghai Climate Center, Xining 810000, P.R.China)

(4: Institute of International Rivers and Eco-Security, Yunnan University, Kunming 650091, P.R.China)

(5: Institute of Qinghai Meteorological Science Research, Xining 810000, P.R.China)

\footnotetext{
Abstract: Ice thickness is an important physical parameter of a lake in the freezing period. It is of great theoretical and practical significance to understand the spatiotemporal characteristics of lake ice, which helps study how lake ice responds to climate under the background of global warming. Based on the ERA5 Climate Reanalysis temperature dataset, MODIS MOD09GQ data product, and ice borehole and radar thickness measurements in 2019, the thickness of lake ice in Lake Qinghai between 2000 and 2019 was reconstructed and the spatial-temporal variation characteristic was analyzed. The results showed that the average growth rate of ice thickness in March $(0.30 \mathrm{~cm} / \mathrm{d})$ was faster than that in February $(0.12 \mathrm{~cm} / \mathrm{d})$ based on the field survey data. The average growth

* 2020-05-05 收稿; 2020-08-03 收修改稿

国家自然科学基金项目 (41861013)、云南大学引进人才科研项目( YJRC3201702)、中国科学院“西部之光”人才培 养引进计划项目和西北师范大学青年教师科研能力提升计划项目 (NWNU-LKQN-14-4) 联合资助.

** 通信作者;E-mail: yaoxj_nwnu@ 163.com.
} 
rate of ice thickness in Lake Qinghai from November 2018 to March 2019 was $0.34 \mathrm{~cm} / \mathrm{d}$ simulated by the degree-day model, with the ice thickness error of $\pm 2 \mathrm{~cm}$ compared with the actual observation data. However, the error was large at the entrance of the river and the south side of Lake Qinghai. Meanwhile, the simulation of ice thickness was overestimated before the mid-March but underestimated later. The annual average ice thickness of Lake Qinghai was 32-37 cm, in which, it fluctuated dramatically in 20082016, showing the tendency of thickening first, then stabilizing and finally thinning. At the beginning of lake freezing, the ice thickness increased rapidly with the growth rate of $0.45 \mathrm{~cm} / \mathrm{d}$ in December and $0.41 \mathrm{~cm} / \mathrm{d}$ in January. After February, the rate slowed down, and it was $0.29 \mathrm{~cm} / \mathrm{d}$ in February and $0.14 \mathrm{~cm} / \mathrm{d}$ in March. On the whole, the ice thickness of Lake Qinghai showed a spatial pattern of being thicker in the north and east, whereas being thinner in the south and west, years of spatial change were more stable in the west than in the east. The average thickness of lake ice was positively correlated with complete freezing duration and the freeze-up period.

Keywords: Lake ice; ice thickness; airborne ice radar; degree-day model; Lake Qinghai

政府间气候变化专业委员会 (IPCC) 第五次评估报告 (AR5) 指出,过去 130 多年全球平均气温升高了 $0.85^{\circ} \mathrm{C}$, 主要升温时间段为 $1983-2012$ 年的 30 年间 ${ }^{[1]}$. 作为大气圈、冰冻圈和水圈的联系纽带, 湖泊通过地 表水的汇聚和蒸发以及地下水汇/渗流等过程参与地表水循环, 并对气候变化响应敏感 ${ }^{[2-3]}$. 青藏高原地区 98 个气象站点观测数据表明, 1982- 2012 年平均气温升幅高达 $1.9^{\circ} \mathrm{C}$, 是全球平均升温幅度的 2 倍 ${ }^{[4]}$. 青藏 高原的自然环境和生态系统在全球占有特殊地位, 该地区也被视作气候变化敏感区 ${ }^{[5-6]}$, 如青藏高原部分湖 泊湖冰物候特征近期表现为开始冻结和完全冻结日期推迟、封冻期减少趋势 ${ }^{[7-10]}$. 青海湖是维系青藏高原东 北部生态安全的重要水体,在保护脆弱的高原湖泊湿地资源、阻挡西部荒漠化向东蔓延和保护鸟类及裸鲤 等生物资源等方面发挥着不可替代作用. 随着西部大开发和丝绸之路经济带的建设, 尤其是兰新高速铁路 的开通, 青海湖已成为旅游热点景区, 而在冬季时有车辆掉人湖中事故发生. 因此, 开展青海湖湖冰厚度研 究不仅对于认识气候变暖背景下的湖冰响应规律具有重要的理论价值,而且对于制定科学合理的冬季青海 湖管理措施具有现实意义.

作为湖泊冻结期的重要物理参数之一, 湖冰厚度不仅反映了水一气界面能量交换强度和物质迁移过程, 而且具有重要的生态价值和经济价值 ${ }^{[11]}$,较其时间属性 (如封冻期和消融期) 难以监测 ${ }^{[12]}$. 传统的冰厚测 量主要采用接触式方法, 如钻孔取冰、电热丝融冰以及压力传感器测厚法等, 此类方法虽测量精度较高, 但 存在效率低、数据量少、损坏冰层等缺点 ${ }^{[13]}$. 随着遥感技术快速发展和测量仪器设备的改进, 一些非接触式 冰厚测量方法开始出现, 如基于冰和水的电导率差别原理采用电磁感应仪测量冰厚, 在水下安装仰视声呐 通过发射声脉冲根据回波时延差确定冰厚, 该类方法仅能用于定点测量, 难以反映湖面冰厚整体分布情 况 $^{[14-15]}$; 卫星数据(如 CryoSat-2 卫星搭载的 Ku 波段 SIRAL) 虽可用于监测大范围湖泊冰厚, 但对薄冰反演 效果较差且难以剔除雪对反照率的影响 ${ }^{[16]}$. 从热力学角度来看, 湖冰是开阔水域在大气和水的相互作用下 通过内能和热能转化达到临界状态的产物, 因此其厚度亦可借助热力学模型来模拟, 如度日法湖冰生长模 型 ${ }^{[17]} 、$ CLIMo 模型 ${ }^{[18]} 、 Z u b o v$ 模型 ${ }^{[19]} 、$ Mylake 模型 ${ }^{[20]}$ 等. 目前国际上对于湖冰厚度的研究主要集中在长时 间序列模拟结果分析及与实测数据的对比, 即模拟精度验证, 或单点测量短时间序列的冰厚特征分析. 如 Dibike 等 ${ }^{[20]}$ 基于 NARR 数据采用 Mylake 模型模拟了北美地区 $\left(40^{\circ} \sim 75^{\circ} \mathrm{N}\right)$ 的湖泊冰厚, 结果表明最大冰厚 普遍分布在 $40 \mathrm{~cm}$ 左右且随着湖深的增加冰厚呈现减小趋势, 其中位于加拿大东西部及较高海拔地区的湖 泊冰厚更大. Duguay 等 ${ }^{[18]}$ 以 Barrow (北极)、Poker Flat Research Range(亚北极)、Churchill(高北森林) 3 个代 表性地区的湖泊为研究对象, 基于研究区附近的气象站点数据采用 CLIMO 模型进行冰厚模拟, 发现随雪深 变化模拟的最大冰层厚度介于 159 $227 \mathrm{~cm}$, 整个冬季平均绝对误差为 $2 \mathrm{~cm}$. 就青海湖而言, 目前系统性的 冰厚观测仍很少, 仅在湖区东南侧的下设水文站有冰厚观测记录, 因人工观测点的单一性、湖冰形成的时空 异质性, 以及人工观测频次较低和观测位置不定, 对于青海湖湖冰厚度时空分布及演化过程仍知之甚少. 本 文基于实测钻孔冰厚数据、飞航式测冰雷达数据和较高时空分辨率的 Terra MODIS 遥感影像, 采用度日法湖 冰生长模型模拟青海湖冰厚变化, 开展冰厚精度评价, 并分析青海湖 2000-2019 年冰厚时空变化规律, 从而 为深人研究青海湖湖冰生消机理提供参考. 


\section{1 研究区概况}

青海湖地处青藏高原东北部 $\left(36^{\circ} 32^{\prime} \sim 37^{\circ} 15^{\prime} \mathrm{N}, 99^{\circ} 36^{\prime} \sim 100^{\circ} 46^{\prime} \mathrm{E}\right)$, 跨青海省刚察、海晏和共和 3 县, 东 西长约 $109 \mathrm{~km}$, 南北宽约 $40 \mathrm{~km}$ (图 1). 根据青海省第一次水利普查公布的 2013 年测量数据, 当水位在 $3193.5 \mathrm{~m}$ 时, 青海湖水域面积为 $4294 \mathrm{~km}^{2}$, 平均水深 $18.3 \mathrm{~m}$, 最大水深 $26.6 \mathrm{~m}$, 蓄水量 $785.2 \times 10^{8} \mathrm{~m}^{3}$, 湖水呈 弱碱性, $\mathrm{pH}$ 值为 9.23 , 含盐量为 $14.13 \mathrm{~g} / \mathrm{L}^{[21]}$, 是中国最大的内陆湖和咸水湖. 青海湖是新构造运动导致周 围山地上升隆起,外泄通道堵塞形成的构造断陷湖, 湖中现有海心山和三块石两个湖心岛, 湖区东面自北向 南依次分布着尔海、沙岛湖、海晏湾和耳海 4 个子湖. 青海湖人湖径流较大的河流主要有布哈河、沙柳河以 及哈尔盖河等, 其中布哈河径流量最大, 约占人湖径流总量的 $60 \%^{[22]}$. 湖区处于我国东部季风区、西北干旱 区和西南高寒区的交汇地带, 属典型的高原半干旱高寒气候 ${ }^{[23]}$, 年平均气温介于 $-1.0 \sim 1.5^{\circ} \mathrm{C}$, 并由东南向西 北逐渐降低, 年降水量为 350 400 mm, 其中夏季降水达 60\% 以上, 年蒸发量可达 $1300 ~ 2000 \mathrm{~mm}$. 因湖水中 含有无机盐类, 青海湖冻结温度比 $0^{\circ} \mathrm{C}$ 稍低, 通常于每年 12 月中旬至 1 月初开始冻结, 12 月底或次年 1 月初 完全被冰层覆盖, 3 月下旬冰层逐渐消融, 至 4 月初或中旬完全消融. 1958-1983 年沙陀寺水文站观测结果 表明,青海湖冰厚一般为 $0.5 \mathrm{~m}$ 左右,最厚达 $0.7 \mathrm{~m}$, 且由岸边向湖心方向逐渐变薄 ${ }^{[24]}$. 基于遥感数据的监测 结果表明 2000-2016 年青海湖封冻期和完全封冻期平均为 $(88 \pm 20)$ 和 $(77 \pm 20) \mathrm{d}$, 湖冰存在期和湖冰消融 期持续时间平均为 $(108 \pm 18)$ 和 $(10 \pm 6) \mathrm{d}^{[10]}$.

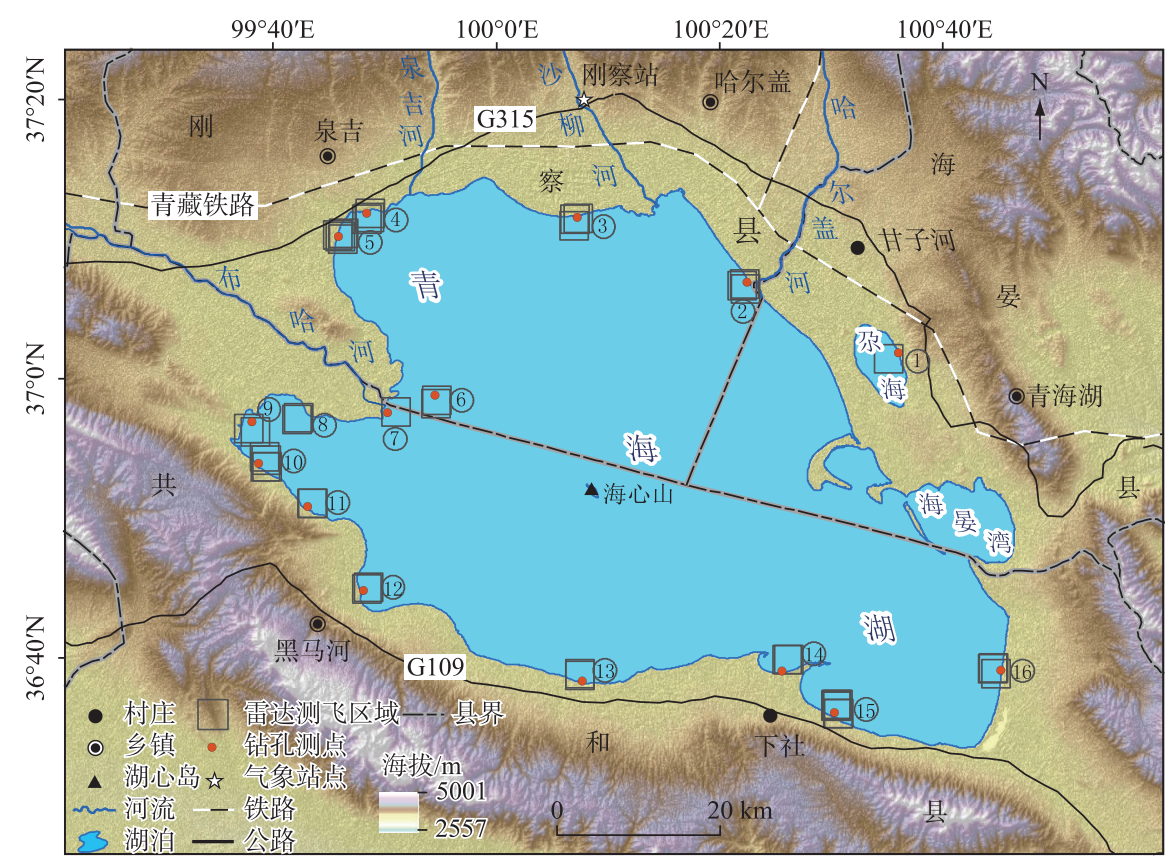

图 1 青海湖及湖冰厚度测区 (点) 分布

Fig.1 Lake Qinghai and distribution of regions and samples of lake ice thickness measurement

\section{2 数据与方法}

\section{1 湖冰钻孔数据与飞航式雷达测厚数据}

2019 年 1 月 13 日- 3 月 24 日期间,在青海湖开展湖冰钻孔测厚和飞航式测冰雷达测厚试验,测厚样点 分布及测飞区域如图 1 所示. 出于工作人员安全考虑和受无人机电池电量限制, 测厚样点及测飞区域绕湖 区周边布设. 为保障钻孔数据与飞航式测冰雷达测厚数据时空一致性, 两项试验同时同地开展, 其中钻孔取 冰厚度采用 $\mathrm{L}$ 型数字式量冰尺 (精度为 $0.01 \mathrm{~mm}$ ) 测量 (图 2a); 飞航式测冰雷达测厚采用 IGPR-30 雷达系 
统, 以无人机为载具平台, 并配备激光测距、GPS 差分定位和高清摄像头等模块, 设备雷达中心频率为 400 $\mathrm{MHz}$, 采样时间间隔为 $2 \mathrm{ps}$, 探测精度可达 $\mathrm{mm}$ 级, 冰层探测厚度 $>6 \mathrm{~m}$ (图 $2 \mathrm{~b}$ ). 该设备的冰厚测量原理是雷 达向下发射高频电磁波, 当到达空气一冰界面和冰一水界面时发生反射, 反射的电磁波信号被天线接收, 假 设雷达波发射至各界面和返回被天线接收所有时间相同, 则冰厚可根据双程走时、冰层介电常数及电磁波 在空气中的传播速度计算得到. 2019 年 1 月 13 日- 14 日,在湖区西北侧及岛岛附近各布设一个 $200 \mathrm{~m} \times 200$ $\mathrm{m}$ 观测场, 并按 $50 \mathrm{~m}$ 等间距在冰面布设标记点, 首先采用飞航式测冰雷达对各标记点冰厚进行测量, 然后钻 孔取冰测量冰厚并用于校正飞航式测冰雷达模拟冰厚的介电常数. 2019 年 1 月 30 日-31 日,在仙女湾、哈 尔盖河人湖口、尔海以及湖区东部进行钻孔取冰测厚 ( 5 个测点) 和雷达测厚 (6个测区) 试验. 2019 年 3 月 1 日-3 日, 在泉吉、鸟岛、布哈河口以及湖区西南部泉湾、峡湾、黑马河、三江源祭海台、二郎剑等地共测点 10 个,雷达测厚区共 8 个. 2019 年 3 月 22 日 - 24 日, 在二郎剑、黑马河、布哈河口、岛岛等地共测飞 7 个区域. 为更好地了解不同方向湖冰厚度分布情况, 飞航式测冰雷达测量时随机采用多种航线 (图 $2 \mathrm{c} \sim \mathrm{f}$ ), 并在每个 测区各测飞 2 次冰厚. 以上湖冰厚度实测数据用于拟合度日法湖冰生长模型参数及模拟结果误差分析.
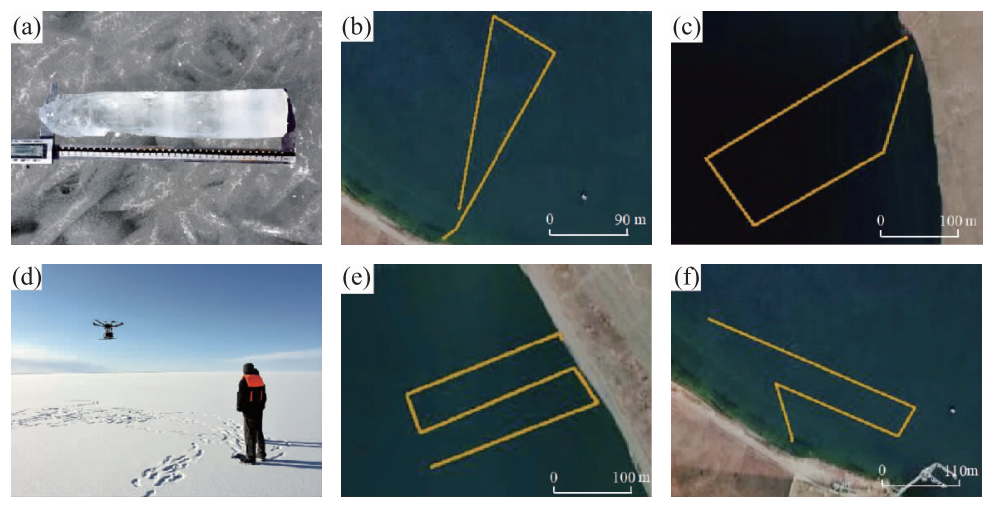

图 2 青海湖冰厚测量照片与无人机航飞路线

Fig.2 Field survey photos of Lake Qinghai ice thickness measurement and flight routes of UAV

\subsection{ERA5 气候再分析资料}

采用 2000-2019 年 ERA5 Climate Reanalysis 数据集中青海湖地区距地面 $2 \mathrm{~m}$ 处气温格点数据作为研 究区气温背景资料, 参考青海湖历年开始冻结和湖冰完全消融日期 ${ }^{[10]}$, 截取该数据集中的每年 10 月 1 日至 翌年 4 月 30 日数据. ERA5 Climate Reanalysis 数据集是欧洲中期天气预报中心 (ECMWF) 于 2017 年发布的

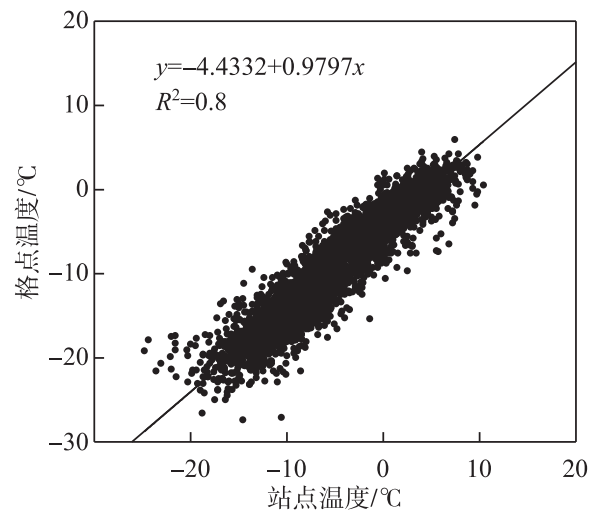

图 3 ERA5 气候数据与观测值的温度对比

Fig.3 Comparison of temperature between ERA5 data and observation
全球气候再分析资料第五代产品,提供了对全球近期气候的 综合数字描述, 时间分辨率为 $12 \mathrm{~h}$, 空间分辨率为 $0.125^{\circ} \times$ $0.125^{\circ}$, 该数据从欧洲中期天气预报中心网站( https://www. ecmwf.int) 下载获得. 因 ERA5 Climate Reanalysis 数据集为 $\mathrm{NC}$ 格式且文件较多, 利用 Python 语言编写脚本程序, 将文 件格式批量转换为 GRID 格式并计算逐格点日均温数据.

距青海湖最近的国家基准站仅有刚察气象站 (图 1), 通 过将 2000-2019 年每年 10 月 1 日至翌年 4 月 30 日站点实 测气温数据与该站点所在 ERA5 气候再分析数据格点对应 分析, 发现二者趋势较为一致 (图 3). 分析结果表明实测数 据与 ERA5 气候数据相关系数为 $0.88(P<0.05)$, 均方根误 差 $(R M S E)$ 为 $5.17^{\circ} \mathrm{C}$, 两组数据间具有较好的相关性且相对 误差较小. 相较于用该气象站点数据来表征青海湖整个湖 面气温数据, ERA5 气候再分析数据分辨率较高, 能够更客 
观地反映青海湖湖面气温变化.

\section{3 光学卫星遥感影像}

为了解青海湖湖面冻结状况及湖冰空间分布情况, 从美国国家航空航天局陆面分布式数据中心 (NASALPDA) 网站 (https://data.giss.nasa.gov) 共下载 2888 景 MODIS MOD09GQ 数据产品, 该数据时间分辨率为 $1 \mathrm{~d}$, 空间分辨率为 $250 \mathrm{~m}$. 此外,从美国地质勘探局 (USGS) 网站 (http://glovis.usgs.gov) 共下载 19 景 20012019 年青海湖封冻期且云量覆盖较小的 Landsat TM/ETM+/OLI 遥感影像, 用于人工目视解译提取青海湖湖 冰范围, 以评估基于 MODIS MOD09GQ 数据提取的湖冰面积占比精度. 鉴于 MODIS MOD09GQ 数据量较大 且需要进行影像拼接, 首先利用 MRT 工具对其进行批量拼接和几何校正, 然后通过编写的 Python 脚本程序 提取湖冰并计算其面积占比.

\section{4 度日法湖冰生长模型}

湖冰可被视作水一气界面的绝缘膜, 湖冰生消改变大气与湖水之间的热量、动量和物质交换 ${ }^{[25]}$, 如湖冰 在生长过程中由于热能损失可改变湖面周围空气的热量. 早在 19 世纪, Stefan ${ }^{[26]}$ 就认为冰的生长过程是一 种特殊的热传导过程, 冰底结冰释放的热量在线性温度梯度情况下通过冰传导出去. Leppäranta ${ }^{[25]}$ 在其研究 中指出, Stefan 提出的理想状态下度日法湖冰生长模型的应用前提是不考虑热惯性和内部热源, 冰层底部水 中没有热通量且冰层顶部的温度已知, 在模拟过程中只考虑温度变化对冰厚的影响, 则冰体每日的生长速 率为:

$$
\rho_{i} \cdot L \cdot \mathrm{d} H / \mathrm{d} t=k_{i}\left(T_{f}-T_{0}\right) / H
$$

式中, $H$ 为冰体厚度; $\rho_{i}$ 为冰体密度; $L$ 为冰体融化潜热; $k_{i}$ 为冰体导热系数; $T_{0}$ 为冰体上表面温度; $T_{\mathrm{f}}$ 为冰体 下表面温度. 若设 $t=0$ 时 $H=H_{0}$ 为初始条件,则式 (1) 的解析式为:

$$
\begin{gathered}
H^{2}=H_{0}^{2}+A_{0}^{2} \cdot S \\
A_{0}=\sqrt{2 k_{i} /\left(\rho_{i} \cdot L\right)} \\
S=\int_{0}^{t}\left[T_{\mathrm{f}}-T_{0}(\tau)\right] \mathrm{d} t
\end{gathered}
$$

若时间间隔 $t$ 为 $1 \mathrm{~d}, S$ 则被定义为水体处于冻结期的负积温 $\left({ }^{\circ} \mathrm{C} \cdot \mathrm{d}\right)$, 冰厚 $H$ 计算可简化为:

$$
H=A_{0} \cdot|S|^{\frac{1}{2}}
$$

式中, $A_{0}$ 为经验常数,在不同冰盖条件下该值介于 $0.7 \sim 2.7 \mathrm{~cm} /\left({ }^{\circ} \mathrm{C} \cdot \mathrm{d}\right)^{\frac{1}{2}}$ 之间 ${ }^{[27]}$.

低温是水由液态转变为固态的必要条件, 如淡水在温度低于 $0^{\circ} \mathrm{C}$ 时就会达到冰点开始冻结, 而海洋和非 淡水湖泊受盐度影响冰点通常则低于 $0^{\circ} \mathrm{C}$. 青海湖为咸水湖, 其冻结水温亦应低于 $0^{\circ} \mathrm{C}$, 该值恰当与否直接 影响度日法湖冰生长模型中负积温的起算温度阈值, 继而影响冰厚模拟精度. 本文采用祁苗苗等 ${ }^{[10]}$ 所用阈 值法提取 2000-2019 年每年 11 月至翌年 4 月青海湖逐日湖冰面积占比, 认为当湖冰面积占比大于 $1 \%$ 时, 表明青海湖水温已达到其冰点. 经统计, 2000- 2018 年 11 月该面积占比对应的最低气温为 $-7.79^{\circ} \mathrm{C}(2009$ 年), 最高气温为 $-0.72^{\circ} \mathrm{C}$ ( 2017 年), 多年平均气温为 $-3.72^{\circ} \mathrm{C}$. 为便于计算, 本文将 $-4^{\circ} \mathrm{C}$ 作为青海湖冻结温 度阈值, 即当连续 $3 \mathrm{~d}$ 日均温 $\leqslant-4^{\circ} \mathrm{C}$ 时开始计算负积温, 连续 $3 \mathrm{~d}$ 日均温 $\geqslant-4^{\circ} \mathrm{C}$ 时停止负积温计算, 得到当 年度最大冰厚. 统计表明, 2000-2019 年负积温平均起算日期为 11 月 9 日,最早为 11 月 5 日 (2014 年), 最 晚为 11 月 12 日 (2017 年); 负积温期平均为 $135 \mathrm{~d}$, 最长和最短天数分别为 $143 \mathrm{~d}$ (2005-2006 年) 和 $127 \mathrm{~d}$ (2009-2010 年). 根据青海湖实测钻孔冰厚数据和雷达测厚数据 (观测期湖泊处于完全冻结状态), 以及冻 结期负积温确定青海湖 $A_{0}$ 值为 $0.9 \sim 1.56 \mathrm{~cm} /\left({ }^{\circ} \mathrm{C} \cdot \mathrm{d}\right)^{\frac{1}{2}}$.

\section{3 结果与分析}

\section{1 基于实测数据的青海湖冰厚时空变化特征}

表 1 为 2019 年 1-3 月青海湖实测冰厚数据,测区编号如图 1 所示. 由表 1 可知,在观测时段内,各采样 点的冰厚总体呈增长趋势, 但各月份冰厚增长速率不同. 1 月 30 日测量数据显示湖区平均冰厚为 $40.2 \mathrm{~cm}, 3$ 月 2 日平均冰厚为 $43.5 \mathrm{~cm}, 3$ 月 22 日为 $51.4 \mathrm{~cm}$, 整个 3 月平均增长速率为 $0.30 \mathrm{~cm} / \mathrm{d}$, 较 2 月份 $(0.12 \mathrm{~cm} /$ d) 增长迅速. 但结果受该时间段内所测区域冰厚影响较大 (可能所测地区均为冰厚较大或较小区域). 空间 
尺度上, 实测冰厚大体呈现北厚南薄、东厚西薄特点. 就各测区平均增长速率而言, 测区 1(2019-01-30)、3 (2019-01-31)、7(2019-03-01) 仅有同一时间段内采样记录(未计算平均增长速率), 平均冰厚分别为42.7、 $46.4 、 49.2 \mathrm{~cm}$. 有两段时间采样记录的测区有 9 个, 可分为 3 个主要变化区: (1) 冰厚快速增长区包括测区 6 、 $13 、 9$, 冰厚平均增长速率均大于 $0.30 \mathrm{~cm} / \mathrm{d}$, 分别为 $0.46 、 0.34 、 0.32 \mathrm{~cm} / \mathrm{d}$. (2) 冰厚平缓增长区平均增长速率 均分布在 $0.25 \mathrm{~cm} / \mathrm{d}$ 左右, 包括测区 $11(0.28 \mathrm{~cm} / \mathrm{d}) 、 10(0.25 \mathrm{~cm} / \mathrm{d}) 、 8(0.21 \mathrm{~cm} / \mathrm{d})$. (3) 冰厚缓慢增长区包 括测区 $12 、 14$, 冰厚平均增长速率仅分别为 $0.15 、 0.11 \mathrm{~cm} / \mathrm{d}$. 测区 $2 、 4 、 5 、 15$ 将 3 个采样时间均包括在内, 其 对应平均冰厚增长速率依次减小, 分别为 $0.30 、 0.24 、 0.12 、 0.08 \mathrm{~cm} / \mathrm{d}$.

表 12019 年 $1-3$ 月青海湖实测冰厚数据

Tab.1 Measured ice thickness data of Lake Qinghai from January to March in 2019

\begin{tabular}{|c|c|c|c|c|}
\hline 实测样区 & 坐标 & 航线长度/km & 日期 & 实测平均冰厚/ $\mathrm{cm}$ \\
\hline \multirow[t]{2}{*}{1} & $37.021^{\circ} \mathrm{N}, 100.593^{\circ} \mathrm{E}$ & - & $2019-01-30$ & 41.5 \\
\hline & $37.014^{\circ} \mathrm{N}, 100.578^{\circ} \mathrm{E}$ & 3.95 & $2019-01-30$ & 43.8 \\
\hline \multirow[t]{4}{*}{2} & $37.109^{\circ} \mathrm{N}, 100.370^{\circ} \mathrm{E}$ & - & $2019-01-30$ & 42.5 \\
\hline & $37.106^{\circ} \mathrm{N}, 100.366^{\circ} \mathrm{E}$ & 4.72 & $2019-01-31$ & 43.0 \\
\hline & $37.101^{\circ} \mathrm{N}, 100.368^{\circ} \mathrm{E}$ & 4.78 & $2019-03-01$ & 50.6 \\
\hline & $37.105^{\circ} \mathrm{N}, 100.362^{\circ} \mathrm{E}$ & 2.60 & $2019-03-24$ & 59.3 \\
\hline \multirow[t]{3}{*}{3} & $37.188^{\circ} \mathrm{N}, 100.118^{\circ} \mathrm{E}$ & - & $2019-01-30$ & 52.0 \\
\hline & $37.186^{\circ} \mathrm{N}, 100.115^{\circ} \mathrm{E}$ & 4.95 & $2019-01-30$ & 43.5 \\
\hline & $37.187^{\circ} \mathrm{N}, 100.120^{\circ} \mathrm{E}$ & 5.17 & $2019-01-31$ & 43.6 \\
\hline \multirow[t]{4}{*}{4} & $37.196^{\circ} \mathrm{N}, 99.804^{\circ} \mathrm{E}$ & - & $2019-03-01$ & 51.5 \\
\hline & $37.191^{\circ} \mathrm{N}, 99.808^{\circ} \mathrm{E}$ & 4.92 & $2019-01-30$ & 35.8 \\
\hline & $37.196^{\circ} \mathrm{N}, 99.810^{\circ} \mathrm{E}$ & 4.72 & $2019-03-01$ & 40.6 \\
\hline & $37.189^{\circ} \mathrm{N}, 99.805^{\circ} \mathrm{E}$ & 3.30 & $2019-03-24$ & 44.4 \\
\hline \multirow[t]{5}{*}{5} & $37.168^{\circ} \mathrm{N}, 99.762^{\circ} \mathrm{E}$ & - & $2019-01-30$ & 42.0 \\
\hline & $37.168^{\circ} \mathrm{N}, 99.765^{\circ} \mathrm{E}$ & 5.18 & $2019-01-31$ & 41.4 \\
\hline & $37.171^{\circ} \mathrm{N}, 99.761^{\circ} \mathrm{E}$ & 5.24 & $2019-02-01$ & 41.0 \\
\hline & $37.172^{\circ} \mathrm{N}, 99.770^{\circ} \mathrm{E}$ & 4.59 & $2019-03-01$ & 46.0 \\
\hline & $37.165^{\circ} \mathrm{N}, 99.769^{\circ} \mathrm{E}$ & 3.2 & $2019-03-24$ & 48.4 \\
\hline \multirow[t]{3}{*}{6} & $36.978^{\circ} \mathrm{N}, 99.904^{\circ} \mathrm{E}$ & - & $2019-03-01$ & 35.0 \\
\hline & $36.972^{\circ} \mathrm{N}, 99.906^{\circ} \mathrm{E}$ & 4.86 & $2019-03-02$ & 42.0 \\
\hline & $36.968^{\circ} \mathrm{N}, 99.905^{\circ} \mathrm{E}$ & 3.51 & $2019-03-24$ & 51.5 \\
\hline \multirow[t]{2}{*}{7} & $36.957^{\circ} \mathrm{N}, 99.833^{\circ} \mathrm{E}$ & - & $2019-03-01$ & 52.5 \\
\hline & $36.958^{\circ} \mathrm{N}, 99.845^{\circ} \mathrm{E}$ & 4.16 & $2019-03-01$ & 45.9 \\
\hline \multirow[t]{2}{*}{8} & $36.952^{\circ} \mathrm{N}, 99.701^{\circ} \mathrm{E}$ & 4.32 & $2019-03-02$ & 55.4 \\
\hline & $36.950^{\circ} \mathrm{N}, 99.697^{\circ} \mathrm{E}$ & 4.70 & $2019-03-22$ & 61.2 \\
\hline \multirow[t]{3}{*}{9} & $36.947^{\circ} \mathrm{N}, 99.631^{\circ} \mathrm{E}$ & - & $2019-03-02$ & 42.3 \\
\hline & $36.936^{\circ} \mathrm{N}, 99.636^{\circ} \mathrm{E}$ & 4.75 & $2019-03-02$ & 48.2 \\
\hline & $36.940^{\circ} \mathrm{N}, 99.626^{\circ} \mathrm{E}$ & 5.46 & $2019-03-22$ & 54.2 \\
\hline \multirow[t]{5}{*}{10} & $36.898^{\circ} \mathrm{N}, 99.640^{\circ} \mathrm{E}$ & - & $2019-03-02$ & 45.2 \\
\hline & $36.902^{\circ} \mathrm{N}, 99.652^{\circ} \mathrm{E}$ & 4.46 & $2019-03-03$ & 47.6 \\
\hline & $36.906^{\circ} \mathrm{N}, 99.649^{\circ} \mathrm{E}$ & 4.42 & $2019-03-03$ & 49.8 \\
\hline & $36.894^{\circ} \mathrm{N}, 99.653^{\circ} \mathrm{E}$ & 5.40 & $2019-03-03$ & 45.5 \\
\hline & $36.894^{\circ} \mathrm{N}, 99.651^{\circ} \mathrm{E}$ & 5.14 & $2019-03-22$ & 54.3 \\
\hline \multirow[t]{3}{*}{11} & $36.846^{\circ} \mathrm{N}, 99.713^{\circ} \mathrm{E}$ & - & $2019-03-02$ & 28.0 \\
\hline & $36.850^{\circ} \mathrm{N}, 99.720^{\circ} \mathrm{E}$ & 4.92 & $2019-03-02$ & 31.0 \\
\hline & $36.850^{\circ} \mathrm{N}, 99.720^{\circ} \mathrm{E}$ & 5.40 & $2019-03-22$ & 37.5 \\
\hline 12 & $36.745^{\circ} \mathrm{N}, 99.795^{\circ} \mathrm{E}$ & - & $2019-03-02$ & 36.2 \\
\hline
\end{tabular}


续表 1

\begin{tabular}{ccccc}
\hline 实测样区 & 坐标 & 航线长度 $/ \mathrm{km}$ & 日期 & 实测平均冰厚/ $\mathrm{cm}$ \\
\hline \multirow{4}{*}{13} & $36.749^{\circ} \mathrm{N}, 99.802^{\circ} \mathrm{E}$ & 4.86 & $2019-03-02$ & 33.2 \\
& $36.747^{\circ} \mathrm{N}, 99.800^{\circ} \mathrm{E}$ & 4.92 & $2019-03-22$ & 39.0 \\
& $36.634^{\circ} \mathrm{N}, 100.118^{\circ} \mathrm{E}$ & - & $2019-03-02$ & 49.2 \\
& $36.641^{\circ} \mathrm{N}, 100.114^{\circ} \mathrm{E}$ & 5.06 & $2019-03-02$ & 47.6 \\
& $36.643^{\circ} \mathrm{N}, 100.114^{\circ} \mathrm{E}$ & 4.48 & $2019-03-22$ & 58.0 \\
14 & $36.643^{\circ} \mathrm{N}, 100.414^{\circ} \mathrm{E}$ & - & $2019-03-02$ & 55.1 \\
& $36.657^{\circ} \mathrm{N}, 100.423^{\circ} \mathrm{E}$ & 3.54 & $2019-03-02$ & 52.7 \\
& $36.657^{\circ} \mathrm{N}, 100.421^{\circ} \mathrm{E}$ & 4.1 & $2019-03-22$ & 57.0 \\
& $36.592^{\circ} \mathrm{N}, 100.490^{\circ} \mathrm{E}$ & - & $2019-03-02$ & 34.2 \\
& $36.602^{\circ} \mathrm{N}, 100.495^{\circ} \mathrm{E}$ & 3.87 & $2019-01-31$ & 32.7 \\
& $36.601^{\circ} \mathrm{N}, 100.493^{\circ} \mathrm{E}$ & 2.74 & $2019-01-31$ & 34.8 \\
& $36.592^{\circ} \mathrm{N}, 100.495^{\circ} \mathrm{E}$ & 4.51 & $2019-01-31$ & 33.5 \\
& $36.603^{\circ} \mathrm{N}, 100.492^{\circ} \mathrm{E}$ & 4.21 & $2019-03-03$ & 34.6 \\
& $36.601^{\circ} \mathrm{N}, 100.492^{\circ} \mathrm{E}$ & 3.48 & $2019-03-03$ & 35.3 \\
& $36.591^{\circ} \mathrm{N}, 100.496^{\circ} \mathrm{E}$ & 3.37 & $2019-03-03$ & 38.0 \\
& $36.601^{\circ} \mathrm{N}, 100.492^{\circ} \mathrm{E}$ & 3.48 & $2019-03-22$ & 49.0 \\
& $36.640^{\circ} \mathrm{N}, 100.737^{\circ} \mathrm{E}$ & - & $2019-01-30$ & 44.3 \\
& $36.643^{\circ} \mathrm{N}, 100.727^{\circ} \mathrm{E}$ & 5.26 & $2019-01-31$ & 45.3 \\
& $36.636^{\circ} \mathrm{N}, 100.730^{\circ} \mathrm{E}$ & 7.53 & $2019-01-31$ & 58.6 \\
\hline $36.642^{\circ} \mathrm{N}, 100.726^{\circ} \mathrm{E}$ & 3.10 & $2019-03-24$ & \\
\end{tabular}

“航线长度”表示飞航式测冰雷达测飞长度, “一”表示钻孔测点无长度.

\subsection{9 年青海湖冰厚模拟结果及精度评估}

图 4 为 2018-2019 年冬季青海湖逐日气温与冰厚模拟值变化. 由该图可知, 2018 年 11 月 8 日青海湖 开始冻结, 当日湖面平均气温为 $-6.44^{\circ} \mathrm{C}, 2019$ 年 3 月 29 日冰厚达到最大值时气温为 $-1.21^{\circ} \mathrm{C}$. 连续负值气 温持续天数为 $141 \mathrm{~d}$, 累计负积温 $-1537.64^{\circ} \mathrm{C}$, 最大冰厚为 $51.05 \mathrm{~cm}$. 将湖区相同位置的冰厚实测值与模拟值 对应分析, 两者之间的相关系数 $R^{2}$ 为 $0.92(P<0.05)$. 在模拟期内, 青海湖冰厚平均增长速率为 $0.34 \mathrm{~cm} / \mathrm{d}$, 负积温绝对值每平均累加 $10^{\circ} \mathrm{C}$ 冰厚增加 $0.25 \mathrm{~cm}$, 其中 2018 年 11 月 8 日- 11 月 21 日及 2018 年 12 月 1 日-12 月 11 日的冰厚日平均增长速率分别为 $0.71 、 0.59 \mathrm{~cm} / \mathrm{d}$, 均大于 $0.50 \mathrm{~cm} / \mathrm{d} ; 2019$ 年 2 月 21 日-3 月 29 日的平均增长速率为 $0.14 \mathrm{~cm} / \mathrm{d}$; 其余时间段内湖冰厚度日平均增长速率介于 $0.20 \sim 0.50 \mathrm{~cm} / \mathrm{d}$ 之间.

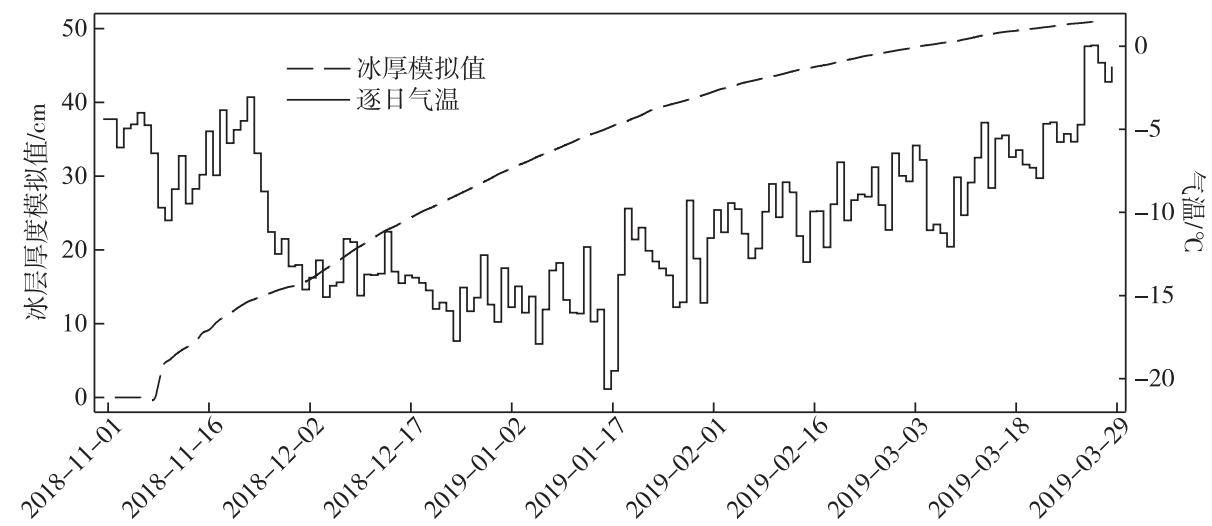

图 4 2018-2019 年冬季青海湖气温变化与冰厚模拟值

Fig.4 Air temperature change and simulated ice thickness of Lake Qinghai in winter season of 2018-2019 
为检验度日法湖冰生长模型模拟的青海湖冰厚精度, 对模拟结果与校正后的雷达测冰厚度数据进行对 比 (图 5 ), 结果表明平均误差为 $\pm 2 \mathrm{~cm}$, 但湖区不同部位冰厚模拟精度有所差异, 其中误差较大区域主要是 布哈河和哈尔盖河人湖口处, 其次是湖区南侧和西南侧. 如 1 月 13 日岛岛附近冰厚误差可达 $10.45 \mathrm{~cm}$, 这可 能与湖冰形成初期厚度较薄以及布哈河淡水补给有关, 布哈河水流汇人湖中不仅通过热量交换使湖水温度 有所上升, 而且可通过动力过程 (如漩涡、湍流) 使冰层底部不断被侵蚀, 从而导致模拟数值大于湖冰实际厚 度. 随着湖冰厚度增加, 模拟精度有所改善, 如鸟岛附近同一测区在 1 月 30 日和 3 月 1 日误差分别为 0.42 $\mathrm{cm}$ 和 $1.35 \mathrm{~cm}$; 湖区其他部位冰厚误差大多介于 $1 \sim 3 \mathrm{~cm}$ 之间. 图 5 的另一个显著特征是, 度日法湖冰生长 模型模拟的冰厚值在 3 月中旬前普遍高估, 而之后则存在低估现象, 如哈尔盖河人湖口处冰厚误差在 1 月 31 日为 $3.28 \mathrm{~cm}, 3$ 月 24 日则为 $-2.23 \mathrm{~cm}$, 这表明湖冰生消不仅与气温相关, 而且受湖面风速、太阳辐射、水 深、湖流等要素影响 ${ }^{[10]}$. 整体而言, 在缺乏多要素观测条件下, 采用度日法湖冰生长模型模拟的湖冰厚度虽 与实测冰厚有所差异, 但其精度亦在可接受范围内, 这为基于气温观测数据预测青海湖湖冰厚度提供了一 种捷径.

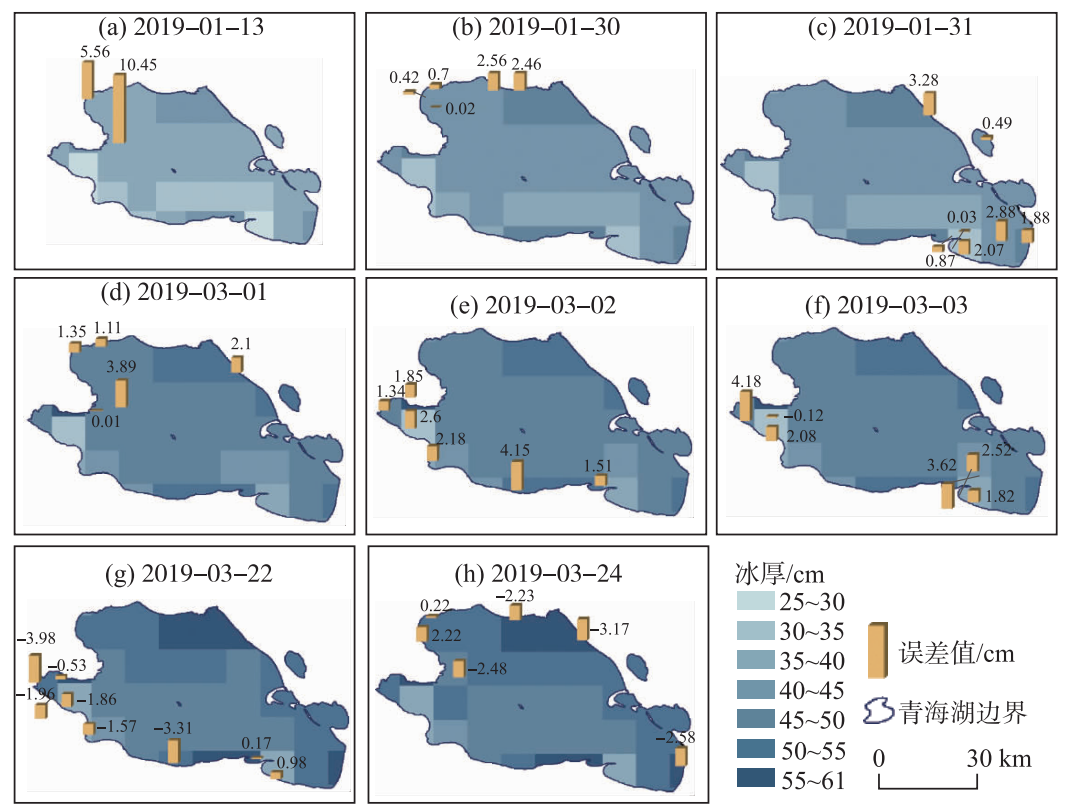

图 52019 年青海湖冰厚模拟及误差

Fig.5 Simulation and error of ice thickness of Lake Qinghai in 2019

\section{$3.32000-2019$ 年青海湖冰厚时空变化特征}

3.3 .1 青海湖湖冰厚度时间变化特征 图 6 为 2000- 2019 年青海湖年际 (当年 11 月至翌年 3 月) 及各月平 均冰厚变化图. 在年际尺度上, 近 20 年青海湖平均冰厚呈波动变化趋势, 平均冰厚介于 $32 \sim 37 \mathrm{~cm}$. 根据平 均冰厚大小,可将此时段划分为 3 个阶段: (1) 2000-2007 年冰厚稳定期,此时段青海湖平均冰厚为 34.65 $\mathrm{cm}$, 最大变幅为 $2.26 \mathrm{~cm}$; (2) 2008- 2016 年冰厚剧烈波动期, 平均冰厚由 2008 年的 $32.78 \mathrm{~cm}$ 快速增长至 2010 年的 $36.43 \mathrm{~cm}$; 之后湖冰厚度稳定处于高值, 2010- 2014 年青海湖平均厚度为 $36.18 \mathrm{~cm}$, 最大变幅仅 $1.38 \mathrm{~cm}$, 其中 2013 年湖冰平均厚度 (37.05 cm) 达到近 20 年最大值; $2015-2016$ 年湖冰平均厚度出现骤降, 两年平均冰厚仅 $32.87 \mathrm{~cm}$, 其中 2016 年为研究时段平均冰厚最小 $(32.08 \mathrm{~cm}$ ) 的年份; (3) 2017-2018 年冰 厚恢复期,此时段青海湖湖冰平均厚度为 $34.79 \mathrm{~cm}$, 略高于第一阶段.

由图 6 亦可知, 青海湖在 11 月份平均冰厚较小 $(10.61 \mathrm{~cm}), 12$ 月份和 1 月份平均冰厚快速增加, 可分 别 达 24.45 和 $37.33 \mathrm{~cm}$, 增厚速率分别为 0.45 和 $0.41 \mathrm{~cm} / \mathrm{d}$; 之后, 2 月份 $(0.29 \mathrm{~cm} / \mathrm{d})$ 和 3 月份 $(0.14 \mathrm{~cm} / \mathrm{d})$ 冰厚变化速率较小, 这两个月的平均冰厚分别为 45.55 和 $50.03 \mathrm{~cm}$. 这表明青海湖在冻结前期 (12 月一翌年 
1 月 ) 冰厚增长迅速, 而中期 (2-3 月 ) 冰厚增长变得缓慢. 湖冰厚度在各月的差异直接导致其平均冰厚在年 际上的不同,如 2010-2014 年平均冰厚最大主要与这一时段 1-3 月冰厚普遍较大有关.

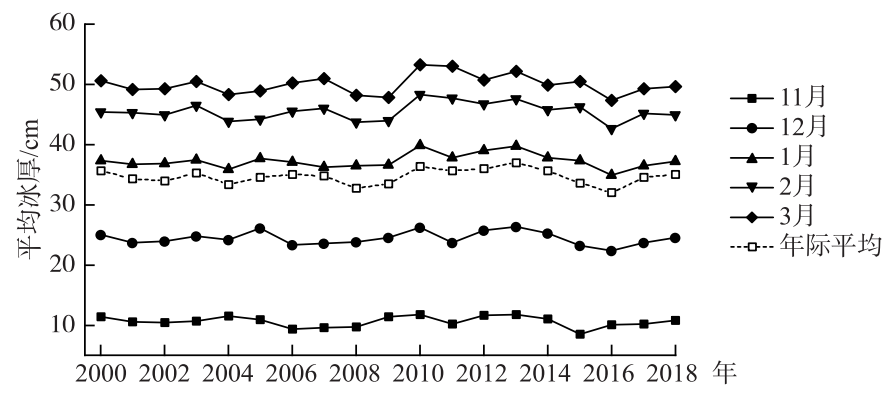

图 $62000-2019$ 年青海湖封冻期年际及各月平均冰厚变化

Fig.6 Variations of annual and monthly average ice thickness of Lake Qinghai during 2000-2019

3.3.2 青海湖湖冰厚度空间变化特征 基于 2000-2019 年 ERA5 Climate Reanalysis 气温数据,采用度日法湖 冰生长模型计算同时段青海湖湖冰厚度可知,近 20 年间青海湖多年平均冰厚在空间上分布不均, 总体上介 于 23 41 cm 之间. 受 ERA5 Climate Reanalysis 气温数据空间分辨率影响, 模拟的湖冰平均厚度与实际冰厚 必然存在差异, 如后者在空间上应为连续变化, 但其仍能反映出青海湖湖冰厚度在空间上的显著差异性, 即 整体呈现北厚南薄、东厚西薄的特点 (图 7). 青海湖冰厚空间分布格局与其冻结消融空间模式密切相关. 已 有研究表明, 青海湖首先在邻近海晏湾的东侧边缘开始冻结, 之后湖区东北部、西北部开始封冻, 湖冰由湖 岸逐渐扩张至湖心 ${ }^{[10]}$. 相应地, 冻结越早和冻结期越长的区域其湖冰越厚. 此外, 湖冰厚度还与湖泊水深、 人湖河流径流及湖下热流分布有关, 如湖区西侧虽冻结较早, 但布哈河河水汇人使该区域冰厚较小; 而湖区 西南侧 (三江源祭海台周边) 湖冰最薄的原因主要是该区域分布有温泉, 高温水流涌人使湖水温度高于其他 湖区, 并不断融化湖冰, 使湖冰厚度难以增大.

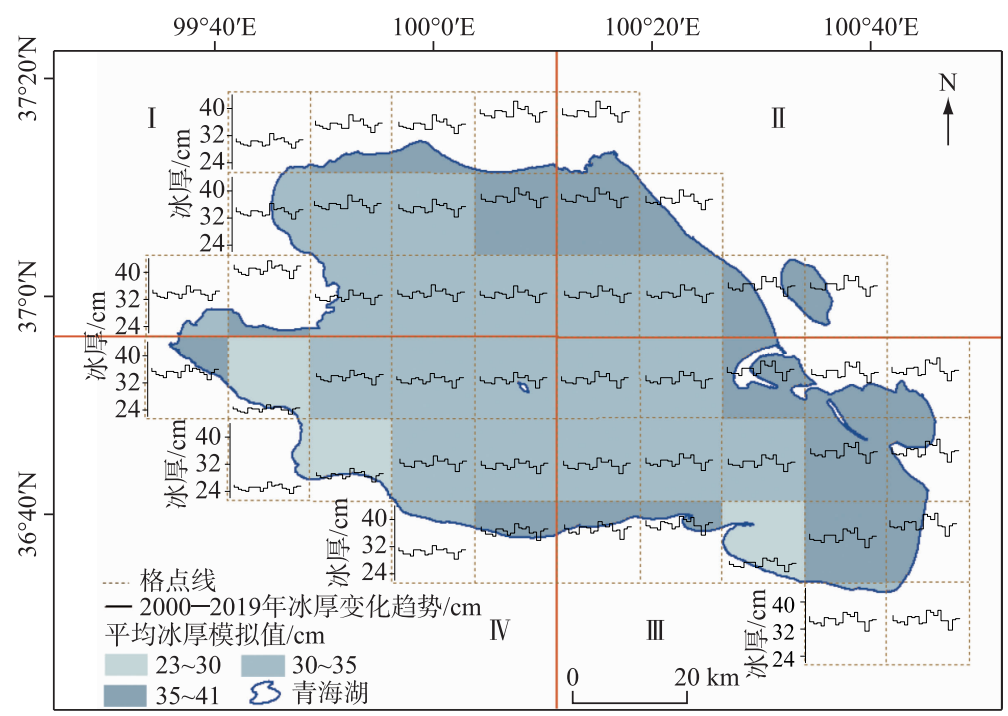

图 $72000-2019$ 年青海湖平均冰厚空间分布及变化趋势

Fig.7 The spatial distribution and trend of average ice thickness of Lake Qinghai during 2000-2019

青海湖各区域 2000-2019 年平均冰厚的变化幅度不同. 以湖泊质心为中心将青海湖划分为 4 个区域, 从左上方开始按顺时针方向分别称为 I、II、III IV 区 ( 图 7). 就多年平均变化速率而言, II 区的平均变化速 
率最快 $(-0.046 \mathrm{~cm} / \mathrm{a})$, IV 区变化速率最慢 $(-0.026 \mathrm{~cm} / \mathrm{a})$, I 区与 III 区平均变化速率分别为 $-0.031 、-0.041$ $\mathrm{cm} / \mathrm{a}$. 年际变化速率最大的区域位于湖区东南角 $(-0.051 \mathrm{~cm} / \mathrm{a})$, 最小的区域则位于西南角 $(-0.019 \mathrm{~cm} / \mathrm{a})$, 各区的变化趋势均为负值, 表明 2000-2019 年青海湖各区域平均冰厚呈减小趋势, 整体而言湖区西部变化 幅度小于东部. 这是由于青海湖湖区东侧没有受到淡水补给以及盛行西北风的扰动, 其冰厚的变化更能体 现出随气候变化的较大变化幅度, 而湖区西侧冰层受到此类干扰因素较多, 在一定程度上减缓了气候变化 所导致的冰厚变化, 从而表现出更为稳定的变化幅度.

\section{4 青海湖冰厚变化与湖冰物候特征的关系}

3.4.1 2000-2019 年青海湖湖冰物候特征 图 8 为 2000- 2019 年每年 11 月至翌年 4 月青海湖逐日湖冰面 积占比及日均温变化曲线, 显然湖泊冻结过程较为缓慢, 而湖冰消融过程则较为迅速. 具体而言, 每年 11 月 份青海湖湖冰面积占比介于 $1 \% \sim 5 \%$ 且波动剧烈, 这主要与湖冰初生过程中冰层较薄, 新生湖冰或碎冰极易 受气温骤升或大风天气影响有关, 导致湖冰在形成初期出现反复冻结消融现象 ${ }^{[11]}$. 至 12 月初, 当湖冰面积 占比达到 5\% 时, 湖冰趋于稳定并随着温度降低湖冰范围逐渐扩大直至完全冻结 (12 月下旬或 1 月上旬). 3 月中下旬, 随着气温上升湖冰开裂消融, 至 4 月上旬或下旬湖冰完全消融.
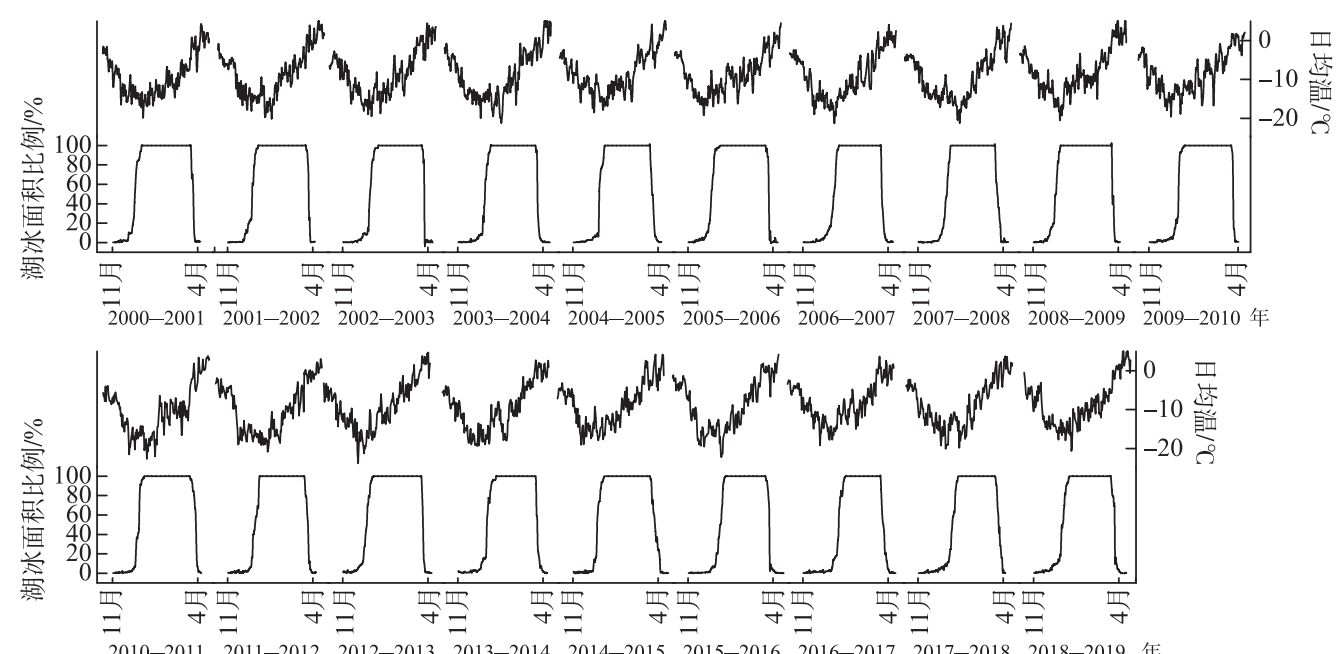

图 8 2000－2019 年青海湖湖冰面积占比及日均温变化

Fig.8 Variations of ice area ratio of Lake Qinghai and daily mean temperature during 2000-2019

前人在研究青海湖湖冰物候特征时以湖冰面积占比达到 $10 \%$ 作为湖泊开始冻结和完全消融日期判别 依据 ${ }^{[10]}$, 此阈值最早由 Reed 等 ${ }^{[28]}$ 在研究北美阿拉斯加西南地区湖冰物候特征时所提出, 其认为当湖冰面 积占比小于 $10 \%$ 时湖冰会出现反复消融冻结现象. 由图 8 可知,当青海湖的湖冰面积占比接近 $5 \%$ 时,湖冰 冻结或消融发展趋势将不会改变, 因此将湖冰面积占比连续 $3 \mathrm{~d}$ 达到 $5 \%$ 定义为湖泊开始冻结日期和湖冰完 全消融日期, 由开始冻结日期至湖冰面积占比首次达到 95\% 的时间间隔定义为冻结时长, 由湖冰面积占比 最后达到 95\%日期至完全消融日期定义为消融时长, 湖冰面积占比介于 $95 \%$ 100\% 的时长则为完全封冻时 长. 统计表明, 近 20 年青海湖平均开始冻结和完全冻结日期分别为 12 月 9 日和 1 月 6 日, 平均开始消融和 完全消融日期分别为 3 月 23 日和 4 月 10 日. 但是, 在个别年份青海湖冻结和消融日期存在较大差异, 如 2016-2017 年开始冻结和完全冻结均最晚,分别为 2016 年 12 月 25 日和 2017 年 1 月 23 日,这应与该年 11-12 月气温偏高有关, 根据距青海湖最近的刚察气象站观测资料, 2016 年 $11-12$ 月平均气温为 $-7.77^{\circ} \mathrm{C}$, 较 2000- 2019 年同期气温偏高 $2.63^{\circ} \mathrm{C}$. 开始冻结和完全冻结最早日期分别为 2012 年 11 月 30 日和 2005 年 12 月 25 日,开始消融和完全消融最早日期均出现在 2016 年,分别为 3 月 15 日和 3 月 22 日,最晚日期分别 为 2012 年 3 月 31 日和 2011 年 4 月 16 日. 尽管 2013-2017 年青海湖开始冻结时间较晚 (多为 12 月中旬)、 开始消融和完全消融时间较早 (分别出现在 3 月中旬和 3 月末), 但整体来看并未发生显著变化, 4 个时间节 
点的变幅均介于 $4 \sim 6 \mathrm{~d}$.

3.4 .2 冰厚变化与湖冰物候特征的关系 从冻结时长、完全冻结时长和消融时长变化 (图 9) 来看, 青海湖冻 结时长明显大于消融时长, 其平均时长分别为 29 和 $11 \mathrm{~d}$, 完全冻结时长平均为 $75 \mathrm{~d}$, 最大和最小时长分别为 $94 \mathrm{~d}(2005-2006$ 年) 和 $50 \mathrm{~d}(2016-2017$ 年). 除个别年份外, 青海湖冻结时长和消融时长虽有所波动, 但 整体变化不大; 完全冻结时长在 2014-2017 年有明显的减少趋势, 且 2004-2006 年也较小, 与之相对应的 刚察气象站 $1-3$ 月平均气温也较高 (普遍高于 $-7.80^{\circ} \mathrm{C}$ ), 较 $2000-2019$ 年 $1-3$ 月平均气温高 $0.66^{\circ} \mathrm{C}$. 与 采用相同数据和方法而國值为 $10 \%$ 的研究结果 ${ }^{[10]}$ 对比,两种结果表现出一定差异性,具体表现为平均开始 冻结日期有所提前 (相差 $7 \mathrm{~d}$ ), 完全冻结日期和开始消融日期基本一致 (相差 $1 \mathrm{~d}$ ), 完全消融日期推后 (相 差 $6 \mathrm{~d}$ ). 平均冻结时长较 $10 \%$ 國值的分析结果长 $14 \mathrm{~d}$, 完全冻结时长短 $2 \mathrm{~d}$, 消融时长仅长 $1 \mathrm{~d}$.

湖冰物候 (封冻期长短) 是影响湖泊冰厚变化的重要因素之一. 根据分析青海湖各年冻结时长、完全冻 结时长、消融时长、封冻期 (湖泊开始冻结至完全消融 ${ }^{[29]}$ ) 和湖冰年平均厚度可知 (图 9), 湖冰厚度与 4 个时 期相关系数 $R^{2}$ 分别为 $-0.05 、 0.13 、 0.06 、 0.23$ ( $P$ 值均小于 0.05 ), 其中冰厚与完全冻结时长及封冻期的相关 性较大, 这是因为湖冰存在的时期越长, 意味着湖泊水面被冰层覆盖的时间越长, 除冰一气间的热量交换外, 湖冰表面的高反射率使冰体吸收的太阳辐射减少, 并进一步加剧近地面气温降低和冰一气热量交换增强, 最 终导致湖冰冻结深度更大. 表明冰厚垂直方向的增厚主要集中于完全封冻期,而冻结期与消融期则表现为 湖冰在湖面水平方向的冻结扩张或消融破裂,故而与厚度变化相关性较低.
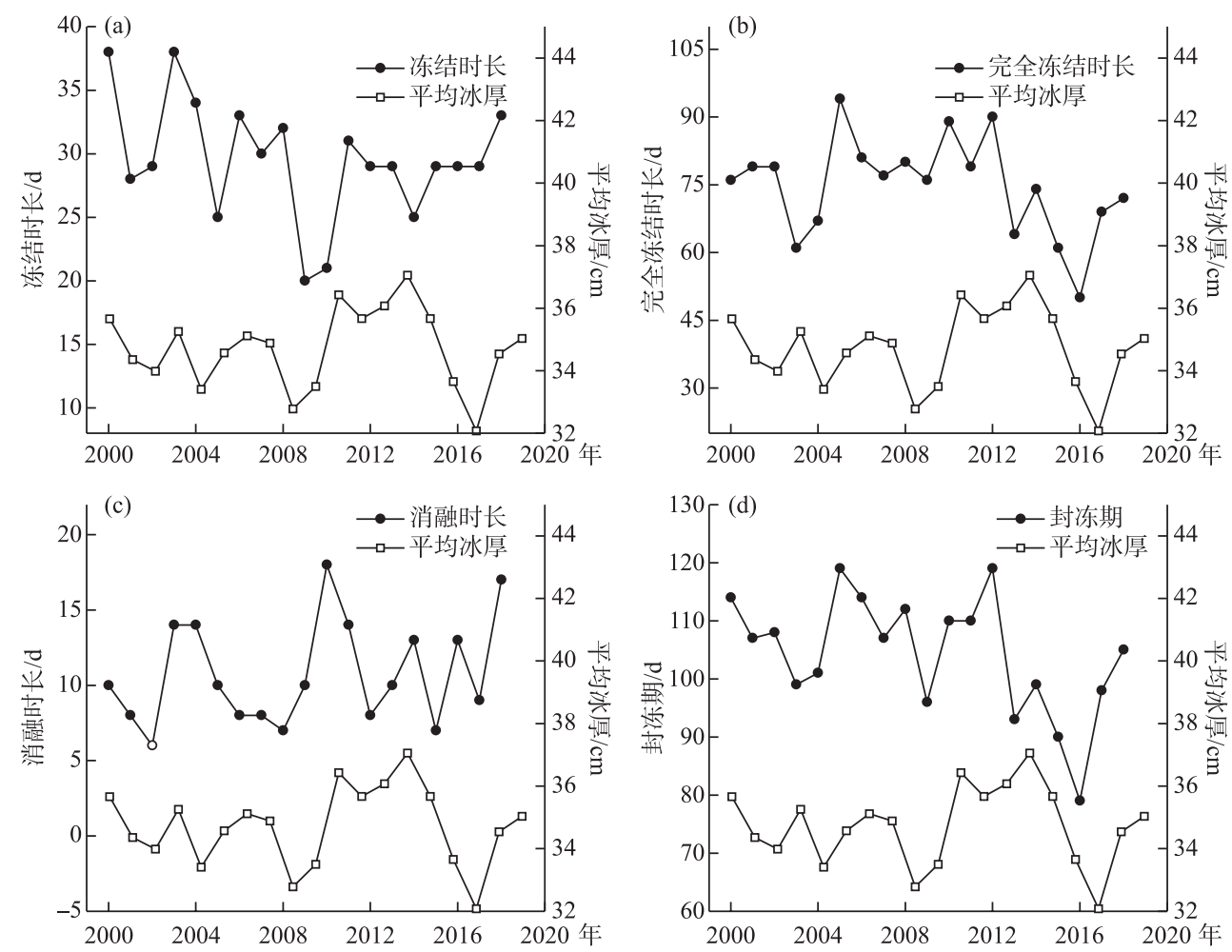

图 9 2000-2019 年青海湖湖冰物候与平均冰厚的关系

Fig.9 Relationship between ice phenology and average ice thickness of Lake Qinghai during 2000-2019

\section{4 讨论}

当湖泊表面被冰覆盖时, 湖冰厚度增长主要取决于热力条件和水力条件, 其中下冰面一湖水界面的热交 换主要是湖冰底部与水流之间的湍流热交换, 冰体内部通过导热完成热量传递, 冰体表面则与大气发生热 
交换,并受气温、风速、短波和长波辐射的吸收反射及云量等条件影响. 研究表明, 冰层垂向热传导通量是驱 动冰层生长的主要能量源, 随着冰厚的增加冰内垂向热传导通量逐渐下降. 当冰厚为 $12 \sim 30 \mathrm{~cm}$ 时, 湖冰上 冰层垂向热传导通量随气温的变化存在明显高频波动特性,而冰厚大于 $30 \mathrm{~cm}$ 的中下冰层波动特性明显衰 减 ${ }^{[30]}$. 青海湖每年 11 月至翌年 1 月气温温度梯度较大, 冰层较薄, 大气与湖水之间的热量传输剧烈, 冰内垂 向热传导通量波动明显, 这导致湖冰的厚度增长速率更快; 而 2-3 月温度梯度变化较小, 当冰厚大于 $35 \mathrm{~cm}$ 时, 冰内垂向热传导通量波动明显衰减导致冰层生长速率减缓.

湖泊水域范围通常具有波动性, 如在丰水期水位上升、面积增大, 而在枯水期则呈相反趋势. 受降水和 冰川融水增加以及蒸发减少等影响, 青藏高原大多数地区湖泊面积近期呈增加趋势 ${ }^{[9,31]}$. 已有研究表明, 1973-2018 年青海湖水位和面积总体呈现先下降 (减少) 后上升 (增加) 趋势, 并大致以 2004 年为界, 20042018 年湖泊水位上升 $2.07 \mathrm{~m}$, 面积增加 $19.59 \mathrm{~km}^{2}, 2018$ 年的水域面积基本与 20 世纪 70 年代末期的面积持 平 ${ }^{[32]}$. 根据 2019 年夏季考察, 青海湖面积仍在持续增加, 鸟岛附近道路、停车场及周边草场均被淹没. 通常, 湖泊水深越大, 其相应的热容也越大, 并直接影响湖冰的生消周期 ${ }^{[9]}$. 通过对比本研究时段内各年青海湖冰 厚与水位变化趋势发现,两者之间并不存在相关性,如 2000-2004 年青海湖水位持续下降,2004 年之后水 位快速上升, 但其冰厚在对应时段内并没有发生类似的变化趋势, 这可能与青海湖盐度较小及平均水深较 浅有关,并导致冰下与湖水热量交换强度微弱.

随着青海湖面积变化, 近年来湖岸线亦发生动态变化. 已有研究表明, 近 45 年来岸线发生变化最大的 区域主要是青海湖东岸的沙岛、西岸的鸟岛和铁布卡湾及北岸沙柳河人口区域, 变化时间点与湖泊面积退 缩及扩张时间一致 ${ }^{[32]}$. 以 2004 年为界, 前期湖岸线向湖内推进, 尤其导致沙岛湖与青海湖主体脱离, 2004 年之后湖岸线持续向外后退, 其中 2017-2018 年是相邻年间岸线变化最大的年份 ${ }^{[31]}$. 青海湖冻结初期较薄 的湖冰会被吹至湖岸边, 沿着湖岸形成岸冰, 而这主要与湖岸线形状和局地盛行风向有关 ${ }^{[28]}$. 湖岸线较为 复杂的区域 (如湖区东部海晏湾、尔海、沙岛及湖区西部的铁卜卡湾) 最先出现岸冰, 且最早形成连续的固定 冰, 上述区域亦为青海湖空间平均冰厚较厚的区域. 虽然研究时段内岸线变化与平均冰厚变化并没有相同 的变化趋势,但岸线变化最大的年份 $(2017-2018$ 年)平均冰厚较前一年增加 $2.46 \mathrm{~cm}$,亦是近 20 年来冰厚 变化较大的年份 (除 2010-2011 年较前一年增加 $2.93 \mathrm{~cm}$ ).

湖冰厚度变化不仅影响温室气体排放强度 ${ }^{[33]}$, 而且通过控制湖面反射率和湖一气间物质与能量交换影 响湖区热量和能量收支平衡 ${ }^{[3,34-35]}$, 并通过改变湖水温度分层控制湖泊生物地球化学的水生生物食物链进 程 ${ }^{[36]}$. 同时对于交通运输, 渔业冬捕、冬季旅游和地方文化认同具有重要意义 ${ }^{[37-38]}$. 近 10 余年青海湖冬季 旅游持续增热, 如地方部门举办冰面徒步穿越青海湖活动, 个别游客也会私自下湖游玩. 尽管青海湖国家级 自然保护区管理局已出台相关政策规范冬季冰上旅游安全, 但每年仍有车辆陷人湖中事故发生, 这一方面 与青海湖范围广阔难以有效监管有关, 另一方面也与游客对青海湖冰厚认识不足有关. 上节分析表明青海 湖通常在每年 1 月中下旬平均冰厚可达 $35 \mathrm{~cm}$ 左右, 其承载能力也会得到极大增强, 因此从 1 月下旬至 3 月 上旬开展冰面活动较为安全. 但需要注意的是, 因青海湖冰厚在空间上的异质性, 在一些湖区应加强游客管 理, 尤其是在湖区西南侧.

\section{5 结论}

本文基于 ERA5 Climate Reanalysis 气温数据集、MODIS MOD09GQ 数据产品和 2019 年湖冰钻孔测厚数 据及雷达测厚数据, 应用度日法湖冰生长模型计算青海湖 2019 年湖冰厚度, 并对 2000-2019 年青海湖冰厚 时空变化进行分析,得到以下结论:

1) 分析 2019 年 $1-3$ 月的实测数据可知, 1 月 30 日湖区平均冰厚为 $40.2 \mathrm{~cm}, 3$ 月 2 日平均冰厚测量值 为 $43.5 \mathrm{~cm}, 3$ 月 22 日为 $51.4 \mathrm{~cm}, 3$ 月平均增长速率为 $0.30 \mathrm{~cm} / \mathrm{d}$, 较 2 月份 $(0.12 \mathrm{~cm} / \mathrm{d})$ 增长迅速. 实测冰厚 空间整体呈现北厚南薄, 东厚西薄的特点. 就冰厚平均增长速率而言, 测区 $1 、 3 、 7$ 仅有同一时间段内观测记 录,有两段时间内观测记录的 9 个测区, 主要有冰厚快速增长区 (测区 $6 、 13 、 9$ )、冰厚平缓增长区 (测区 11 、 $10 、 8$ )、冰厚较慢增长区 (测区 $12 、 14$ ). 测区 $2 、 4 、 5 、 15$ 包含 3 段采样时间, 其对应平均冰厚增长速率依次 减小. 
2) 2018 年 11 月 -2019 年 3 月湖冰厚度平均增长速率为 $0.34 \mathrm{~cm} / \mathrm{d}$, 与实测数据相比模拟冰厚平均误差 为 $\pm 2 \mathrm{~cm}$, 但在湖区不同区域模拟精度有所差异, 其中误差较大区域为布哈河口、哈尔盖河人湖处, 以及湖区 西南部以及湖区南部. 同时, 冰厚模拟数值存在 3 月中旬前高估而之后低估现象.

3) 2000-2019 年青海湖年平均冰厚为 32 37 cm, 年际变化呈波动趋势, 其中 2000-2007 年为冰厚稳 定期, 2008- 2016 年为冰厚剧烈波动期, 2017-2018 年为冰厚恢复期. 青海湖冻结前期冰厚增长迅速, 12 月 与 1 月湖冰增长速率分别高达 0.45 和 $0.41 \mathrm{~cm} / \mathrm{d} ; 2$ 月后冰厚增长速率放缓, 2 月和 3 月的增长速率分别为 0.29 和 $0.14 \mathrm{~cm} / \mathrm{d}$, 这与冰层垂向热传导通量在不同深度冰层内随气温变化的波动频率密切相关. 青海湖湖 冰平均厚度在空间上存在显著差异,整体表现为北厚南薄、东厚西薄的空间格局, 且湖区西部冰厚变化幅度 小于东部.

4) 近 20 年青海湖平均开始冻结和完全冻结日期分别为 12 月 9 日和 1 月 6 日,平均开始消融和完全消 融日期分别为 3 月 23 日和 4 月 10 日, 平均冻结时长和消融时长分别为 29 和 $11 \mathrm{~d}$, 完全封冻时长平均为 75 d. 湖冰平均厚度变化与完全封冻时长以及封冻期相关性较高, 而与冻结时长及消融时长相关性较小, 表明 冰层增厚主要集中于完全封冻期,冻结期与消融期则为湖冰在湖面的冻结扩张或消融破裂.

湖冰演化是一个极为复杂的过程,尽管本文模拟了 2000-2019 年青海湖冰厚空间分布特征及变化趋 势, 但因度日法湖冰生长模型仅考虑气温对冰厚的影响, 并未考虑冰体内部导热过程及冰下的热力与水力 作用, 不能模拟消融期的冰厚变化及未能考虑积雪存在对冰厚模拟的影响, 这使得模拟结果与真实湖冰厚 度存在一定差异, 在未来模拟青海湖湖冰厚度时应加以考虑. 同时, 受试验观测区域限制, 对青海湖中间大 片区域的冰厚模拟结果仍有待验证.

致谢: 在开展湖冰测厚试验期间, 青海湖国家级自然保护区管理局和刚察县气象局工作人员、大连中睿科技 发展有限公司陈洁博士及云南大学祁苗苗博士给予了大量帮助, 在此致以谢忱.

\section{6 参考文献}

[ 1 ] IPCC. Climate change 2013: The physical science basis//Stocker T, Qin D eds. Working Group I Contribution to the Fifth Assessment Report of the Intergovernmental Panel on Climate Change. Cambridge: WMO/UNEP, 2013.

[ 2 ] Sharma S, Blagrave K, Magnuson JJ et al. Widespread loss of lake ice around the Northern Hemisphere in a warming world. Nature Climate Change, 2019, 9(3) : 227-231. DOI: 10.1038/s41558-018-0393-5.

[ 3 ] Lang JH, Lyu SH, Li ZG et al. An investigation of ice surface albedo and its influence on the high-altitude lakes of the Tibetan Plateau. Remote Sensing, 2018, 10(2) : 218. DOI: 10.3390/rs10020218.

[ 4 ] Chen BX, Zhang XZ, Tao J et al. The impact of climate change and anthropogenic activities on alpine grassland over the Qinghai-Tibet Plateau. Agricultural and Forest Meteorology, 2014, 189/190: 11-18. DOI: 10. 1016/j. agrformet. 2014. 01.002 .

[ 5 ] Zhang GQ, Yao TD, Xie HJ et al. Estimating surface temperature changes of lakes in the Tibetan Plateau using MODIS LST data. Journal of Geophysical Research: Atmospheres, 2014, 119(14) : 8552-8567. DOI: 10.1002/2014JD021615.

[ 6 ] You QL, Min JZ, Kang SC. Rapid warming in the Tibetan Plateau from observations and CMIP $_{5}$ models in recent decades. International Journal of Climatology, 2016, 36(6) : 2660-2670. DOI: 10.1002/joc.4520.

[ 7 ] Guo LN, Wu YH, Zheng HX et al. Uncertainty and variation of remotely sensed lake ice phenology across the Tibetan Plateau. Remote Sensing, 2018, 10(10) : 1534. DOI: 10.3390/rs10101534.

[ 8 ] Cai Y, Ke CQ, Duan Z. Monitoring ice variations in Lake Qinghai from 1979 to 2016 using passive microwave remote sensing data. Science of the Total Environment, 2017, 607/608: 120-131. DOI: 10.1016/j.scitotenv.2017.07.027.

[ 9 ] Yao XJ, Li L, Zhao J et al. Spatial-temporal variations of lake ice in the Hoh Xil region from 2000 to 2011. Acta Geographica Sinica, 2015, 70(7): 1114-1124. DOI: 10.11821/dlxb201507008. [姚晓军, 李龙, 赵军等. 近 10 年来可可西里 地区主要湖泊冰情时空变化. 地理学报, 2015, 70(7): 1114-1124.]

[10] Qi MM, Yao XJ, Li XF et al. Spatial-temporal characteristics of ice phenology of Lake Qinghai from 2000 to 2016. Acta Geographica Sinica, 2018, 73(5) : 932-944. DOI: 10.11821/dlxb201805012. [祁苗苗, 姚晓军, 李晓锋等. 20002016 年青海湖湖冰物候特征变化. 地理学报, 2018, 73(5): 932-944.]

[11] Qin DH, Dong WJ, Luo Y eds. Climate and environment changes in China: 2012 volume I scientific basis. Beijing: Chi- 
na Meteorological Press, 2012. [秦大河, 董文杰, 罗勇. 中国气候与环境演变: 2012 第一卷 科学基础. 北京: 气象 出版社, 2012.]

[12] Laxon S, Peacock N, Smith D. High interannual variability of sea ice thickness in the Arctic region. Nature, 2003,425 (6961) : 947-950. DOI: 10.1038/nature02050.

[13] Li ZJ, Han M, Qin JM et al. States and advances in monitor of ice thickness change. Advances in Water Science, 2005,16 (5) : 753-757. [李志军, 韩明, 秦建敏等. 冰厚变化的现场监测现状和研究进展. 水科学进展, 2005, 16(5): 753-757.]

[14] Worby AP, Griffin PW, Lytle VI et al. On the use of electromagnetic induction sounding to determine winter and spring sea ice thickness in the Antarctic. Cold Regions Science and Technology, 1999, 29(1) : 49-58.

[15] Feng CH, Liu Q, Ge YC. Research on ice thickness detection technology based on upward looking sonar. Acoustics and Electronics Engineering, 2017, (3) : 4-7. [冯常慧, 刘强, 葛印超. 基于仰视声呐的冰厚探测技术研究. 声学与电子 工程, 2017, (3) : 4-7.]

[16] Beckers JF, Casey JA, Haas C. Retrievals of lake ice thickness from Great Slave Lake and Great Bear Lake using CryoSat2. IEEE Transactions on Geoscience and Remote Sensing, 2017, 55(7) : 3708-3720.

[17] Li CY, Yang F, Shi XH et al. Impact of seasonal ice cover on nutrient distribution in Ulansuhai Lake. Journal of Hydroelectric Engineering, 2016, 35(11): 1-8. [李畅游, 杨芳, 史小红等. 乌梁素海覆冰特征及其对营养盐分布的影响分 析. 水力发电学报, $2016,35(11): 1-8$.]

[18] Duguay CR, Flato GM, Jeffries MO et al. Ice-cover variability on shallow lakes at high latitudes: model simulations and observations. Hydrological Processes, 2003, 17: 3465-3483.

[19] Gary AM. The surface heat and mass balance. Boston: Springer, 1986.

[20] Dibike Y, Prowse T, Bonsal B et al. Simulation of North American lake-ice cover characteristics under contemporary and future climate conditions. International Journal of Climatology, 2012, 32(5) : 695-709. DOI: 10.1002/joc.2300.

[21] Qinghai Provincial Water Resources Department, Qinghai Provincial Bureau of Statistics. The first water resources census bulletin of Qinghai Province. Qinghai Statistics, 2015，(10): 34-39. [ 青海省水利厅, 青海省统计局. 青海省第一次 水利普查公报. 青海统计, 2015, (10): 34-39.]

[22] Chen XM, Han B, Wang LL et al. Analysis on the correlation between total phosphorus, water temperature, mineralization and chlorophyll-a in Lake Qinghai, China. Journal of Agro-Environment Science, 2013, 32(2) : 333-337. [ 陈学民, 韩 冰, 王莉莉等. 青海湖总磷、水温及矿化度与叶绿素 a 相关性分析. 农业环境科学学报, 2013, 32(2): 333-337.]

[23] Yi WJ, Li XY, Cui BL et al. Climate change and impact on water level of the Lake Qinghai watershed. Journal of Arid Meteorology, 2010, 28(4) : 375-383. [伊万娟, 李小雁, 崔步礼等. 青海湖流域气候变化及其对湖水位的影响. 干旱 气象, $2010,28(4): 375-383$. ]

[24] Chen XZ, Wang GY, Li WJ et al. Lake ice and its remote sensing monitoring in the Tibetan Plateau. Journal of Glaciology and Geocryology, 1995, 17(3) : 241-246. [陈贤章, 王光宇, 李文君, 等. 青藏高原湖冰及其遥感监测. 冰川冻土, $1995,17(3): 241-246$.

[25] Leppäranta M. A review of analytical models of sea-ice growth. Atmosphere-Ocean, 1993, 31 (1): 123-138. DOI: 10. 1080/07055900.1993.9649465.

[26] Stefan J. Ueber Die Theorie der Eisbildung, insbesondere über Die Eisbildung im Polarmeere. Annalen Der Physik, 1891, 278(2) : 269-286. DOI: 10.1002/andp.18912780206.

[27] Michel B, Ramseier RO. Classification of river and lake ice. Canadian Geotechnical Journal, 1971, 8(1) : 36-45.

[28] Reed B, Budde M, Spencer P et al. Integration of MODIS-derived metrics to assess interannual variability in snowpack, lake ice, and NDVI in southwest Alaska. Remote Sensing of Environment, 2009, 113(7) : 1443-1452. DOI: 10.1016/j. rse.2008.07.020.

[29] Lei RB, Li ZJ, Zhang ZH et al. Comparisons of thermodynamic processes between lake ice and landfast sea ice around Zhongshan station, east Antarctica. Chinese Journal of Polar Research, 2011, 23 (4) : 289-298. DOI: 10.3724/SP. J. 1084.2011.00289. [雷瑞波, 李志军, 张占海等. 东南极中山站附近湖冰与固定冰热力学过程比较. 极地研究, $2011,23(4)$ : 289-298.]

[30] Kropáček J, Maussion F, Chen F et al. Analysis of ice phenology of lakes on the Tibetan Plateau from MODIS data. The Cryosphere, 2013, 7(1) : 287-301. DOI: 10.5194/tc-7-287-2013. 
[31] Zhu LP, Zhang GQ, Yang RM et al. Lake variations on Tibetan Plateau of recent 40 years and future changing tendency. Bulletin of Chinese Academy of Sciences, 2019, 34(11): 1254-1263. [ 朱立平, 张国庆, 杨瑞敏等. 青藏高原最近 40 年湖泊变化的主要表现与发展趋势. 中国科学院院刊, 2019, 34(11): 1254-1263.]

[32] Qi MM, Yao XJ, Liu SY et al. Dynamic change of Lake Qinghai shoreline from 1973 to 2018. J Lake Sci, 2020, 32(2): 573-586. DOI: 10.18307/2020.0225. [祁苗苗, 姚晓军, 刘时银等. 1973-2018 年青海湖岸线动态变化. 湖泊科学, $2020,32(2): 573-586$.

[33] Ducharme-Riel V, Vachon D, del Giorgio PA et al. The relative contribution of winter under-ice and summer hypolimnetic $\mathrm{CO}_{2}$ accumulation to the annual $\mathrm{CO}_{2}$ emissions from Northern Lakes. Ecosystems, 2015, 18(4) : 547-559.

[34] Weyhenmeyer GA, Meili M, Livingstone DM. Nonlinear temperature response of lake ice breakup. Geophysical Research Letters, 2004, 31(7).

[35] Wang W, Lee X, Xiao W et al. Global lake evaporation accelerated by changes in surface energy allocation in a warmer climate. Nature Geoscience, 2018, 11(6): 410-414.

[36] Hamilton DP, Magee MR, Wu CH et al. Ice cover and thermal regime in a dimictic seepage lake under climate change. Inland Waters, 2018, 8(3) : 381-398.

[37] Magnuson JJ, Robertson DM, Benson BJ et al. Historical trends in lake and river ice cover in the northern hemisphere. Science, 2000, 289(5485): 1743-1746.

[38] Brammer JR, Samson J, Humphries MM. Declining availability of outdoor skating in Canada. Nature Climate Change, 2014, 5: 2-4. 